somewhat less in using a photographic theodolite than in using our instruments. But on the other hand our method enables us to observe the clond; even in twilight and moonlight, in rain and storm. Also, it is, no doubt, much cheaper than the photographic one.

Up ala, November 6

\section{The Helm Wind}

Some years ago I passed a summer at Melmerby, which is about the best place for seeing the " helm," which is incorrectly described as affecting the Penrith valley (for, in fact, it never cxtencls to Penrith) by your correspondent, M. Woeikoff.

Nelmerby is at the foot of the Cross Fell range, and gets the "helm" with great violence. When an easterly wind comes on, the summit of Cross Fell becomes clouded; it puts on its $1 \mathrm{clm}$ : then from this a violent cold wind pours down the hillside (which is steep) and rises up again at no great distance. At Melmerby, and places similarly situated, there is clear sky, for the moisture in the sky is invisible, but further from the range it is precipitated where the current rises, and there is cloudy sky, without the strong wind. The phenomenon is, in fact, precisely that at Table Mountain, where the cloud on the crest is called the "table-cloth."

Judging from M. Woeikoff's description there seems to be a difference in the phenomena. Probably owing to the gentle slopes of the Varada chain the air does not seem to rise again, and there is no cloud-bank parallel to the chain. It would seem, too, that the wind extends to the revest, unless there is a misprint.

37, Hamilton Road, Ealing, W., November I3 J. F. TENNANT

\section{THE MODE OF ADMISSION INTO THE ROYAL SOCIETY}

$\mathrm{O}$

UR contemporary Science, in the last number which has reached this country, makes some remarks concerning the admission of candidates into the Royal Society, against which, in the interests of truth and accuracy, it is our duty to protest, the more especially as it is also implied that the French system of canvassing those who are already Fellows of the Society is also adopted.

The statements actually made are (I) that there is an "actual competitive examination, on the result of which a certain number of successful candidates are annually chosen," and (2) "that the English method has the additional disadvantage that it does not secure the men whom it is most desirable to honour." We read also, "During the schoolboy period the distinction between different individuals is a distinction of learning, and an examination is not unfitted to discover the boy who deserves reward. But learning is not the quality which a State needs to make it great. Casaubons are not the kind of men who have built up English science. The qualities which ought to be encouraged, and which it should be a nation's delight to honour are qualities too subtle to be detected by a competitive examination."

For the benefit of our transatlantic brethren we may as well state the facts as we know them. For reasons into which we need not enter here, as they do not affect the question at issue, nearly forty years ago the Royal Society determined to limit the yearly admissions to fifteen; and to throw upon the Council the responsibility of selecting the fifteen who are to be nomiriated for election, a general meeting of the Society reserving to itself the right of confirming or rejecting such nomination. It may be instructive to remark that for thirty years that right has not been exercised.

The way in which the matter is worked is as follows:The friends of a man, who are already in the Society, and who think he is entitled to the coveted distinction, prepare a statement of his services to science, in many cases without consulting him in any way. 'This paper thus prepared is sent round to other Fellows of the Society, who are acquainted with the work of the candi- date, and who sign it as a testimony that they think he is worthy of election. In this way when the proper time arrives some fifty or sixty papers are sent in to the Council for their consideration. In the Council itself we may assume that the selection of the fifteen is made as carefully as possible in view not merely of individunl claims but of the due representation of the different branches of science. It is not for us to state the safeguards or mode of procedure adopted, but we think we may say that the slightest action or appeal to any member by the candidate himself would be absolutely fatal to his election. Finally, we may say that, years back, when a heavy entrance fee had to be paid, there were cases in which the question had to be put to one whose friends were anxious to see him elected, whether he would accept election. The small yearly subscription of $3 l$., now the only sum payable, makes even this question unnecessary at the present time.

\section{ON MEASURING THE VIBRATORY PERIODS} OF TUNING-FORKS

THE tuning-fork when its number of double vibrations, to and fro, in a second, or briefly its frequency, has been ascertained, is a most convenient instrument for measuring minute divisions of time. As such it is now extensively used for physical, physiological, and military purposes (velocity of bullets and cannon balls). The antecedent difficulty of ascertaining the frequency, is however very great. The old processes, sufficient for roughly ascertaining musical pitch, and depending upon wires of known weight, length, and tension, or the action of the siren, are totally insufficient for modern purposes. It was the contradictory nature of the results furnished by the monochord in the division of the Octave into twelve equal parts that led Scheibler to his system of a series of tuning-forks differing from one another by known numbers of vibrations, leading to countable beats, and extending over an Octave. Nothing can be more convenient to use than such a series of forks for all musical purposes. They enable the frequency not only of any small as well as large tuning-fork, but also of any sustained tone to be ascertained within one-tenth of a vibration, that is, one vibration in ten seconds. The writer has for some years been in the constant habit of using such a set of forks with the most satisfactory results. His own forks were measured by Scheibler's (exhibited in the Historic Loan Collection of Musical Instruments at the Albert Hall this year), but extend over a greater range, from about 224 to about $588 \mathrm{vib}$., that is, rather more than an Octave and a major Third. The great advantage of such a tonometer is extreme portability, immediate application to any sustained tone (even that of a pianoforte string), and the independence of the result from any (almost always imperfect) estimation of unison by a musical ear. There are of course antecedent difficulties in ascertaining the pitch of each particular fork, but these are overcome by patient observation, the extension of the series beyond an Octave furnishing in itself the required check.

Scheibler died in I 837 . In 1879 Prof. Herbert MacLeod and Lieut. R. G. Clarke, R.E. (Proc. R. Soc., vol. xxviii. p. 29I, and Philosoph. Trans., vol. clxxi. p. I) invented an optical arrangement, which under proper management (but the manipulation was very difficult) gave excellent results for large tuning-forks, like those of Koenig. And in 1880 Koenig (Wiedemann's Annalen, 1880, pp. 3944r7) invented a clock method for ascertaining with extreme accuracy the frequency of one large standard fork of 64 vib. at $20^{\circ} \mathrm{C}$. Before both Prof. MacLeod and Dr. Koenig, Prof. Alfred Mayer, of Hoboken, New Jersey, U.S., had invented a most careful and ingenious electrographic method, of which a full account has just appeared in vol. iii. of the Transactions of the National Academy 
of Sciences, U.S. ${ }^{1}$ Briefly this last method consists, first of making the tuning-fork itself, by means of an added style of extreme tenuity, scribe its vibrations as sinuosities in a curve on a revolving cylinder of smoked paper, an old conception; and, secondly, of determining the exact number of such sinuosities as occurred in a second, by means of electricity, which was entirely new, and in which lies the pith and difficulty of the method.

When in 1879 the writer was collecting materials for his "History of Musical Pitch" (Fourn. of Soc. Arts, March 5 and April 2, 1880, and January 7, I88I), it became necessary to verify Scheibler's forks, and to do so he had five large forks constructed, giving the pitches of certain forks preserved in the Conservatoire at Paris. These forks he measured with great care by Scheibler's tonometer, and then Prof. MacLeod measured them by his process, after which they were sent to America to be measured by Prof. Mayer (the particulars of his measurements of these forks are given in his paper cited above), and on their return they were remeasured by the writer with the scribing-points on, and by Prof. MacLeod with the scribing points on and off, in order to ascertain the flattening caused by the scribing-points, and also any losses that might have been occasioned by the journey. The sum of the two affected only the second place of decimals, except in one fork, where they amounted to 02 vibrations, By adding these, and also correcting for temperature, the result was an agreement of all the three methods within $0^{\circ} I$ vibrations. ${ }^{2}$

But Prof. Mayer's results are given to three places of decimals, which it would be extremely difficult to check, not only because of the delicacy of the measurement, but on account of the alteration of pitch by temperature, and the uncertainty which prevails over the coefficient of alteration. Thus for $\mathrm{I}^{\circ} \mathrm{F}$. Prof. Mayer considers this coefficient to be 00004638 , or I in $2156 \mathrm{I}$; Prof. MacLeod takes $I$ in 20,490 , and Dr. Koenig as $I$ in $I 6,097$, or in I6, I 12, or 16,000 . The writer's own experiments, between $59^{\circ}$ and $175^{\circ} \mathrm{F}$., gave $\mathrm{I}$ in 18,280 . For all ordinary purposes $I$ in 20,000 may be conveniently used. But the coefficient certainly alters with the size, shape, and quality of the fork observed, and hence it is necessary to correct each observation for temperature separately, before taking the mean, as Prof. Mayer has done. Under these circumstances, at most 2 places of decimals (perhaps only I) out of 3 of Prof. Mayer's means can be trusted. That is, it is doubtful whether his process for measuring the frequency of tuning-forks is superior to Scheibler's, properly carried out.

The difficulties of the process, which caused Prof. Mayer much trouble to overcome, may now be referred to. The kernel of the method consists in a very exact assignment of the beginning and end of each second on the sinuous curve of vibrations. This is obtained from a clock, the rate of which has to be ascertained. Its pendulum is armed with a point which cuts through a globule of mercury in a cup, screwed up to be small and rigid, and, as this globule rapidly becomes oxidised, by the passage of electricity, it must be renewed for each experiment. The spark from the inductorium at every contact of the pendulum and mercury, must make a single perforation of the smoked paper covering the cylinder. To effect this the strength of the current must be carefully regulated, as otherwise a great number of holes may be made. The paper is very interesting on this point, which is well illustrated by experiments and a diagram. Other

"On a method of precisely Measuring the Vibratory Periods of Tuning Forks, and the determination of the Laws of the Vibrations of Forks; with special reference of these Facts and Laws to the Action of a Simple Chronoscope."

2 Prof Mayer measured, at temperatures varying from $63^{\cdot} \cdot 3 \mathrm{~F}$. to $69^{\circ} 25 \mathrm{~F}$. The standard temperature of the writer was $59^{\circ} \mathrm{F} .=15^{\circ} \mathrm{C}$, the temperature at which the Diapason Normal in Paris has been settled. It may be mentioned that in Prof. Mayer's tables xiii. and xiv. of this paper, the titles have been transposed; the first related to the Tuileries fork, 434 vib., and the second to the Feydeau fork, $422 \cdot 8 \mathrm{vib}$, and not conversely as printed. precautions are necessary, but the above two are the most important. The primary coil of the inductorium and the clock (through the pendulum and globule of mercury) are placed in the circuit of a voltaic cell. The fork and cylinder (separated from the style by the thickness of the smoked paper) are placed in the secondary circuit of the inductorium. The work of the fork on the paper in scribing was found not to flatten by more than 004 vib. The flattening from the appended scribing-point was shown by Prof. MacLeod's measurements of the writer's forks to vary from 021 to 0475 vib. It therefore always sensibly affected the second place of decimals, showing that the results for determining the frequency of an unarmed fork, when the effect of the arming could not be determined (as it cannot be by Prof. Mayer's method), could not be trusted beyond one decimal place. This limit can be reached very simply without all this apparatus and these precautions, by simply counting the beats of good forks within beating distance of each other. Prof. Mayer's method, therefore, does not surpass Scheibler's for simply determining the frequency of tuning-forks, but is fully equal to it, provided the forks are sufficiently large. Neither Prof. Mayer's nor Prof. MacLeod's process is applicable to small forks. The writer is doubtful whether the passing of a current through one prong of the fork and not the other may not affect the period of the fork. I he necessity of screwing the fork on to a block (as indeed of screwing it into a resonance box) is always dangerous from the possibility of twisting the prongs. The writer has known of a fork which was thus considerably altered. The frequency of a fork screwed on to block in this way is not the same as that of a fork on a resonance box. Prof. Mayer has himself, in his paper, determined that the amount of correction for support and scrape may amount to - -026 vib. Prof. Mayer does not renew the excitation with a bow during the same observation, as Prof. MacLeod had to do, and he has shown that the frequency is practically independent of the amplitude of vibration.

Prof. Mayer did not himself apply his instrument to determine the frequency of forks generally, but, as he states in the title of his paper, specially as a chronoscope. In that case the above difficulties disappear. What is wanted to know is the exact number of vibrations of the scribing-fork as it scribes, affected by all the circumstances mentioned--screwing, scribing, passage of electricity, \&c. We are not in the least concerned to discover the frequency of the unscrewed, unarmed, unelectrified fork. Even temperature is of no consequence, provided it be uniform during the experiment. The velocity of rotation of the cylinder is also immaterial, provided it be constant for one double vibration, which can hardly help being the case for such a small fraction of a second. There is only one source of error, the inequality of the seconds' pendulum, arising from the globule of mercury being of a sensible magnitude, so that an appreciable time is occupied in traversing it (eliminated by counting the sinuosities for every two seconds instead of every second), and the inevitable want of true centering of the globule and pendulum (eliminated by taking a mean). Prof. Mayer's arrangement then becomes an extremely simple and also an extremely accurate means of measuring short intervals of time within, to a certainty, onehundredth of a vibration of the fork. Thus, if the fork gives 400 vibrations in a second, the measurement would be correct to one-forty-thousandith part of a second!

Prof. Mayer concludes his very valuable and interesting paper-which is recommended to the attention of all experimenters requiring accurate chronoscopic observations -with showing the arrangement for experimenting with this chronoscope "on the velocities of fowling-piece shot of various sizes projected with various charges of powder from 12 - and Io-gauge guns," with a diagram giving the 
position of the wires and make-circuit lever, and tables of the results, and says, finally :-

"The simplicity and inexpensiveness of the chronoscope we have described in this paper, its accuracy, and the ease with which it is used, must commend it to all who will give it a trial under the conditions of the action which we have endeavoured to set forth in this paper. Another of its advantages is that its records on the paper covering the cylinder are easily rendered permanent by drawing the unsmoked side of the paper over the surface of a dilute solution of photographic negative varnish contained in a wide shallow dish. On the records may be written with a blunt style the nature of the experiments they record before the carbon is fixed by the varnish, and then they can be bound together in book-form for preservation and reference."

Alexander J. Ellis

\section{HINTS ON THE CONSTRUCTION AND EQUIPMENT OF OBSERVATORIES FOR AMATEURS}

I F it were necessary to offer any apology for the short series of articles of which the first is now presented to the readers of NATURE, it might be found in the fact that, so far as I know, nothing fulfilling the above title has been put into circulation in England for more than forty years. This is the more remarkable when one considers the great development of astronomy in this country during the present generation, a development the credit of which is far more due to amateur effort than to the influence of Governments or public establishments. The reason I have fixed upon the year I 844 is that that was the year in which Admiral Smyth published his wellknown "Bedford Catalogue of Celestial Objects," to which he prefixed certain chapters dealing with the construction and management of small observatories.

Those chapters have never been reproduced in any form, partly, no doubt, for the reason that they are a good deal out of date; but they are still capable of furnishing many useful hints to any one who wishes to write on the subject of observatories.

It is not too much to say that the Bedford Observatory has directly or indirectly served as the model for nearly all the private observatories of moderate dimensions since erected in England, and it is equally certain that, whatever may be the changes which considerations of finance, or architecture, or geology, may render expedient in particular instances, no important alterations need be made in the main features of the Bedford Observatory, although upwards of half a century has elapsed since it was erected, and more than forty years have passed away since it was pulled down.

In order to compress as much information as possible into a small compass I propose to classify what I have to say in such a way as shall successively conduct the reader step by step through the stages which he himself will have to pass through between the time when he determines to erect an observatory and the time when he finds himself the happy possessor of the completed building. Of telescopes as such I shall here say nothing, and the only other prefatory remark which seems requisite is this: that an amateur astronomer with only a given and moderate sum of money to lay out will do well to appropriate an adequate part of his funds to the purchase of a fairly good stand and of a suitable structure in which to house his instruments, rather than spend too much on his tube and then be obliged to starve the stand and to put up with inadequate shelter from the weather or no shelter at all. To begin, therefore, at the beginning.

The Choice of $a$ Site.-As to this the amateur will probably in most cases be obliged to suit himself as best he can. If his garden offers any varieties of site, he should endeavour to secure one on slightly rising ground, with an uninterrupted horizon to the south (for meridian purposes) and to the west (for comets and inferior planets in the vicinity of the sun at sunset). A clear horizon to the east is of less moment, unless searches for comets before sunrise are intended to be systematically carried out.

In making preparations for building an astronomical observatory-and occasionally, indeed, for other purposes -it is necessary to know how to set out a meridian line. Of course this may be done by means of a mariner's compass (correcting for the magnetic deviation); but there are other ways of doing this independently of a compass, and as it is not always easy to ascertain the deviation a statement of at any rate one of these other ways, as given by Challis, will be useful. Set up a pole at the spot through which the proposed meridian line is required to pass, using a plumb-line to ensure the pole being vertical. Draw around the pole as a centre several concentric horizontal circles, and mark the points of coincidence of the extremity of the shadow of the pole with these circles both before and after noon. Then if the two points on each circle be joined by a chord the mean of the directions of the middle points of the chords from the pole will be approximately the direction of the meridian line. This method answers best about midsummer when the sun's diurnal path is high in the heavens, and the change of declination is small. A little forethought must be displayed in suiting the dimensions of the circles to the height of the vertical pole employed.

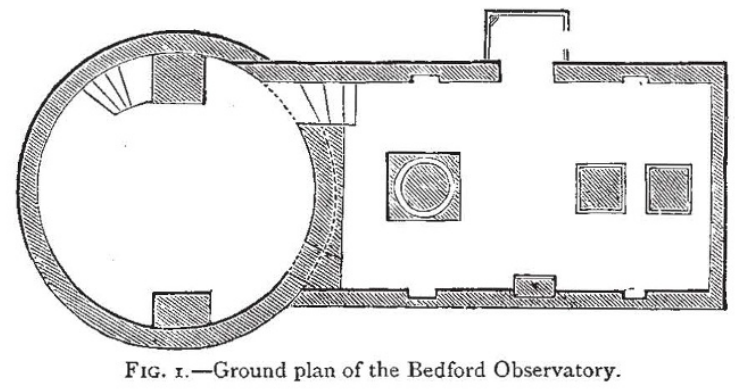

Foundations. - The foundations of an observatory are a matter of great importance, and unless a rock ${ }^{1}$ or chalk bottom can be readily obtained, an artificial bottom of concrete, more or less thick according to the height of the intended superstructure, must be made. This of course applies to the piers which are to carry instruments. In the case of the observatory itself, especially if the material of the fabric is to be of wood, which is so often used, the ordinary precautions against settlement taken by a competent builder will suffice. As no fire-place is permissible in an observatory because of the disturbing currents of air to which fires give rise, special precautions must be taken to protect the building and its contents against damp, and the consequences thereof. In heavy clay soils clear away the soil all around the outside of the observatory by making a trench, say Io feet wide and 4 feet deep, and fill up the excavation with broken bricks, coarse gravel, or other hard porous material. Provide by suitable gutters and pipes, that all rain-water falling on the observatory shall be carried away to a distance as quickly as possible.

Details of the Structure of the Observatory.-Fig. I. represents the ground plan and Fig. 2 the elevation of the Bedford Observatory. The external dimensions were about 35 feet by 13 feet 6 inches. The building was divided into two apartments: (I) an equatorial room, circular, and 15 feet in diameter on the inside; and (2) a transit-room, 17 feet by 12 feet on the inside, and 10 feet

$x$ A rock foundation is not necessarily the most stable possible, and some authorities deem a sandy substratum best. 